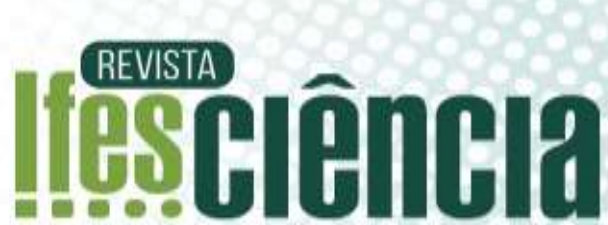

\section{NARRATIVAS DIGITAIS PARA O ENSINO DE SAÚDE NA ESCOLA: UMA PROPOSTA DE INTERVENÇÃO VOLTADA À FORMAÇÃO DE EDUCADORES}

\author{
DIGITAL NARRATIVES FOR THE TEACHING OF HEALTH IN SCHOOL: AN \\ INTERVENTION PROPOSAL TURNED FOR THE FORMATION OF \\ EDUCATORS
}

\author{
Patricia Oliveira Branquinho Silva \\ Universidade Federal do Triângulo Mineiro. E-mail: pattybranquinho@gmail.com
}

Artigo submetido em 05/03/2019, aceito em 15/06/2019 e publicado em 23/12/2019.

\begin{abstract}
Resumo: Este trabalho baseia-se na percepção de que o aperfeiçoamento do professor é um requisito próprio dessa profissão. Após um processo de pesquisa e observação com o intuito de conhecer a realidade da escola observada, percebeu-se que apesar de alguns professores fazerem o uso das tecnologias de informação e comunicação na escola, a maior parte não fazia o uso dos recursos de maneira adequada. O caminho metodológico utilizado na pesquisa foi de cunho qualitativo, resultado de uma pesquisa ação voltada para as tecnologias, culturas e saúde na escola, desenvolvido durante o Curso de Especialização em Tecnologias Educacionais para a Prática Docente do Ensino em Saúde na Escola da Escola Nacional de Saúde Pública Sergio Arouca da Fundação Oswaldo Cruz. Visando uma mudança no processo ensino aprendizagem por meio TDICs, este trabalho pretende contribuir com adequação do uso das tecnologias na escola observada com o intuito de motivar as aulas, bem como promover a formação dos professores. O trabalho tem a intenção, acima de tudo, auxiliar na possibilidade de construção e mudanças de novas práticas pedagógicas no processo de ensino aprendizagem com o objetivo de melhoria no rendimento escolar e a adequação dos recursos tecnológicos disponíveis.
\end{abstract}

Palavras-chave: Ensino de Saúde; narrativas digitais; TDICs; formação de professores; ensinoaprendizagem.

\begin{abstract}
This work is based on the perception that the improvement of the teacher is a specific requirement of this profession. After a process of research and observation in order to know the reality of the observed school, it was noticed that although some teachers make use of information and communication technologies at school, most of them did not use the resources properly. The methodological path used in the research was qualitative in nature, the result of an action research focused on technologies, cultures and health at school, developed during the Specialization Course in Educational Technologies for Teaching Practice in Health at the School of the Sergio Arouca National School of Public Health of the Oswaldo Cruz Foundation. Aiming at a change in the teaching and learning process through TDICs, this work aims to contribute to the adequacy of the use of technologies in the school observed in order to motivate classes, as well as to promote the training of teachers. The work aims, above all, to assist in the possibility of building and changing new pedagogical practices
\end{abstract}


in the learning teaching process with the objective of improving school performance and the adequacy of available technological resources.

Keywords: Health teaching; digital narratives; TDICs; teacher training; teaching-learning.

\section{INTRODUÇÃO}

A sociedade atual globalizada vive um processo de avanço tecnológico abrangente. Esse processo não deixa de atingir uma das suas instituições mais importantes, a escola. Dos computadores às redes sociais, os sistemas, os dispositivos e os processos digitais, todos foram responsáveis por mudanças na sociedade e em todas as suas esferas institucionais.

As mudanças acerca do trabalho vão desde novos métodos de executar uma mesma função ao fim de certas funções, deixando até de existir. As técnicas e tecnologias vão se superando ao decorrer do tempo e o mundo do trabalho vai sendo modificado e atingindo também o trabalhador, suas habilidades, capacidades e suas funções. Como afirma Libâneo (2014, p.17):

É verdade que o mundo contemporâneo - neste momento da história denominado hora de sociedade pós-moderna, pós-industrial ou pósmercantil, ora de modernidade tardia está marcado pelos avanços na comunicação e na informática e por outras tantas transformações tecnológicas cientificas. Essas transformações intervêm nas várias esferas da vida social, provocando mudanças econômicas, sociais, políticas, culturais, afetando, também as escolas e o exercício profissional da docência.

As mudanças contemporâneas com relação ao saber impactam diretamente a educação, pois com as mudanças nas relações surgem também novos ambientes, novos modos de interações, novos espaços de conhecimentos e novos modos de ensinar e aprender.

As mudanças acerca da Educação perpassam pelos processos de ensino e aprendizagem, modificando a natureza do ambiente. As tecnologias de informação e comunicação disponibilizam possibilidades de novos meios e modos de ensinar e aprender. Essas transformações atingem diretamente o profissional docente, pois o processo de ensino e aprendizagem depende de habilidades e competências, principalmente do profissional que está à frente desse compromisso. Segundo Libâneo (2008, p.75):

O professor é um profissional cuja atividade principal é o ensino. Sua formação inicial visa a propiciar os conhecimentos, as habilidades e as atitudes requeridas para levar adiante o processo de ensino aprendizagem nas escolas.

Nesse sentido, sabe-se que no Brasil, um dos grandes problemas na Educação é a formação de professores, um assunto que vem sendo debatido há mais de um século bem como a qualidade dos cursos de formação de docentes (BORGES e col. 2011, SAVIANI, 2009). Porém a qualidade da educação no país ainda é questionável. Como descreve Gatti, Barreto e André (2000, p.27):

O Brasil ainda está distante de uma qualidade educacional considerada razoável, sobretudo no que se refere às redes públicas de ensino, que atendem à maioria das crianças e dos jovens brasileiros. Vários são os fatores intervenientes nessa situação, entre eles a questão dos docentes, sua formação e suas condições de trabalho.

As circunstâncias de trabalho dos professores no país vêm sofrendo um processo de precarização contínuo, principalmente com a questão salarial e a jornada de trabalho. Outros processos também afetam a sua condição de trabalho; no aspecto sociocultural as mudanças de paradigmas provenientes da globalização e do avanço tecnológico. 
No tocante às mudanças, no trabalho docente, procedentes da globalização e do avanço tecnológico, são modificações que causam efeitos diretamente no discente, tendo em vista que o papel do professor é criar condições para que o processo de ensino e aprendizagem seja efetivo conforme o mundo atual exige. De acordo com Libâneo (2008, p.81):

\begin{abstract}
As novas exigências educacionais diante dessas transformações pedem um professor capaz de exercer sua profissão em correspondência às novas realidades da sociedade, do conhecimento, do aluno, dos meios de comunicação e de informação. Por isso, nos dias de hoje, a sociedade requer um professor atualizado.
\end{abstract}

A atual circunstância tecnológica da Educação exige um professor capaz de proporcionar a aprendizagem no mesmo contexto tecnológico em que vive o aluno contemporâneo. Por ser um profissional em constante formação, o professor, atualmente, precisa ter consciência de que os seus saberes e competências estão ou não em harmonia com o seu aluno.

O aluno contemporâneo é um aluno diferente dos alunos de outrora, pois ele nasce num contexto tecnológico moderno em relação aos outros. Já nasce conectado a uma nova realidade em que as ferramentas lhe permitem aprender de outra maneira, ele é um nativo digital.

Diante do cenário descrito acima, dada a importância da formação de professores no atual contexto tecnológico de informação e comunicação, bem como a formação e a capacitação do aluno para ele, pois é na escola que o aluno começa a ser preparado para cidadania e para o trabalho, surgiu a motivação para esse estudo. Buscam-se formas alternativas de qualificação para que os professores compreendam as tecnologias de informação e comunicação e façam o uso de forma adequada.

\subsection{SITUAÇÃO GERADORA}

Durante o curso de especialização em Tecnologias Educacionais para a Prática Docente do Ensino em Saúde na Escola da Escola Nacional de Saúde Pública Sergio Arouca da Fundação Oswaldo Cruz (ENSP/FIOCRUZ), foi desenvolvida uma pesquisa ação com o intuito de conhecer a realidade de uma escola, observada sob os seguintes aspectos: cultura da escola e na escola, saúde e tecnologia no contexto escolar. Ao final do trabalho, por meio de uma pesquisa ação percebeu-se que apesar de alguns professores fazerem o uso das tecnologias na escola, a maior parte não fazia o uso dos recursos de maneira adequada. Diante dessa situação real, foi notório o interesse dos professores em questão em adquirir novas habilidades e competências, fato visto no período de observação da pesquisa.

\subsection{JUTIFICATIVA}

A justificativa para a realização deste trabalho deve-se ao fato de que, nos dias atuais, dado a globalização e o avanço tecnológico, se faz necessário o professor esteja em harmonia com seus alunos, visto que esses alunos são nativos digitais. Após vivenciar por um ano a falta de uso e o uso inadequado dos recursos tecnológicos de uma escola situada em uma zona rural no município de Uberaba- MG percebeu-se a urgência em se discutir a formação de professores para o uso das tecnologias digitais de informação e comunicação (TDICs).

Para além dessa equiparação técnica do professor, refletir sobre o processo evolutivo da formação de professores no país possa fazer com que se busque compreender as circunstâncias em que tudo ocorreu. Mas também, possa colaborar em novas discussões com o intuito de surgirem novas perspectivas e possibilidades de melhoria nas condições de trabalho $\mathrm{e}$ formação dos professores brasileiros. O objetivo desse estudo é contribuir com o 
ensino de saúde por meio de narrativas digitais.

\subsection{PROBLEMATIZAÇÃO E PROBLEMA}

Foi verificado que na da Escola $X$, localizada na zona rural, no município de Uberaba- MG, o uso das TDICs na escola não é satisfatório, a maior parte dos professores não faz o uso dos recursos tecnológicos de maneira adequada.

Dada a importância das tecnologias no mundo de hoje e julgando ser necessária uma fonte de motivação para os professores e alunos. Com o auxílio da metodologia de ensino Storytelling por meio das TDICs, espera-se que este trabalho contribua na ocorrência de mudança no ensino aprendizagem.

De que forma a aplicação da metodologia de ensino Storytelling por meio das TDICs pode auxiliar os professores da Escola $X$, no município de Uberaba-MG, no ensino da temática saúde?

\section{TECNOLOGIAS DE INFORMAÇÃO E COMUNICAÇÃO NA EDUCAÇÃ̃O}

\begin{tabular}{lllr}
\multicolumn{2}{c}{ Recentemente o mundo } & vem \\
passando por um conjunto & de \\
transformações & denominado & de
\end{tabular}
globalização, junto com isso vêm também as mudanças causadas pelo avanço da tecnologia. Desde o início da história são essas mudanças na vida do homem que o fizeram chegar aos dias de hoje. Para Libâneo (2008, p.45):

Essas transformações, que ocorrem em
escala mundial, decorrem da
conjunção de um conjunto de
acontecimentos e processos que
acabam por caracterizar novas
realidades sociais, políticas,
econômicas, culturais, geográficas.

Com o avanço tecnológico, os aspectos econômicos, políticos, culturais e sociais da sociedade também se modificam, de acordo com Moran (1995, p.24): "não são as tecnologias que mudam a sociedade, mas a sua utilização dentro do modo de produção capitalista, que busca o lucro, a expansão, a internacionalização de tudo o que tem valor econômico". Tendo em vista, a sociedade capitalista, são transformações em vários âmbitos da vida do homem que de um momento para outro muda a realidade em que ele vive.

Atualmente vivemos na era digital, para o homem moderno tanto a informática quanto a internet são essenciais para sua vida nessa época. $\mathrm{Na}$ era da informação dispomos de inúmeros recursos visuais e auditivos e o uso dentro da educação foi inevitável, pois as mudanças causadas pelas revoluções também estão modificando a educação de forma geral bem como a maneira de ensinar e aprender. Para Moran (1995, p.25):
As tecnologias de comunicação não mudam necessariamente a relação pedagógica. As Tecnologias tanto servem para reforçar uma visão conservadora, individualista como uma visão progressista. A pessoa autoritária utilizará o computador para reforçar ainda mais o seu controle sobre os outros. Por outro lado, uma mente aberta, interativa, participativa encontrará nas tecnologias ferramentas maravilhosas de ampliar a interação.

As tecnologias digitais de informação e comunicação TDICs na educação passam a ser um meio mais produtivo em diversos aspectos. Podem ser utilizadas desde nas tradicionais burocracias das instituições até no processo pedagógico através de novas técnicas de ensino aprendizado, práticas pedagógicas, visando o aprimoramento humano.

Partindo do princípio de que, os jovens em seu âmbito, já estão integrados às tecnologias, de modo geral, produzindo e criando linguagens próprias e tendo em vista o ajustamento do uso das TDICs nas escolas, nada mais oportuno do que fomentar o interesse dos jovens no uso das TDICs no contexto escolar nesse momento. 


\subsection{MÍDIAS NA EDUCAÇÃO}

No mundo atual e globalizado é quase impossível desvincular a comunicação da tecnologia, as tecnologias de informação e comunicação (TICs) estão está cada vez mais presente na vida dos indivíduos. Com o crescimento do uso das TICs na sociedade, no Brasil, é na escola que uma parcela da população tem a oportunidade de acesso às novas tecnologias.

O uso das mídias na educação tem o intuito de integrar os novos conhecimentos tecnológicos, tecnologias de informação e comunicação, com os conhecimentos básicos dos currículos escolares das instituições de ensino do país. As mídias são, para Setton (2010, p.07):

[...] todo aparato simbólico e material relativo à produção de mercadorias de caráter cultural. Como aparato simbólico, considero o universo das mensagens que são difundidas com a ajuda de um suporte material como os livros, CDs etc. [...]; ou seja, todo um campo da produção de cultura que chega até nos pela mediação de tecnologias, sejam elas as emissoras de $\mathrm{TV}$, rádio ou internet.

Com a entrada dos computadores, notebooks, tabletes e celulares na educação, aparelhos capacitados com recursos, softwares, que substituem milhares de cadernos, planilhas e agendas foi imprescindível a produção do trabalho sem eles. A internet também se tornou essencial, com sua rapidez e conteúdo vasto, ela se tornou um meio a mais de ensinar e aprender.

As tecnologias digitais de informação e comunicação TDICs na educação podem ser utilizadas no processo pedagógico através de novas técnicas de ensino aprendizado, práticas pedagógicas, visando o aprimoramento humano. De acordo com Setton (2010, p.10): "a prática de transmitir conhecimentos e valores que as mídias se propõem é um ato pedagógico e, portanto, também comunicativo". A comunicação de sentidos e valores faz parte da educação.

Para Libâneo (2011, p.55): "a educação e a comunicação sempre andaram juntas na reflexão pedagógica". É por meio da comunicação que o ser humano transmite, ensina e aprende a sua cultura, nada mais pedagógico, pois por pedagogia entende-se a teoria e a prática da educação.

\subsection{FORMAÇÕES DE PROFESSORES: NOVA REALIDADE}

Tendo em vista um aluno que já nasce incorporado num contexto tecnológico, o professor contemporâneo desse aluno deveria ser um professor capaz de proporcionar a aprendizagem no mesmo contexto tecnológico em que vive. Por ser um profissional em constante formação, o professor, atualmente, necessita ter consciência de que os seus saberes e competências estão ou não em harmonia com os do seu aluno para atingir os objetivos da aprendizagem.

Num contexto tradicional ou tecnológico moderno, o professor é o responsável pelo processo de ensino e aprendizagem. Sendo assim, o professor, tem que estar preparado para ele. Nessa nova realidade tecnológica e de comunicação há uma exigência de novas funções, tanto a escola quanto o professor sofreram mutações. Conforme Libâneo (2011, p. 30):

O novo professor precisaria, no mínimo, de adquirir sólida cultura geral, capacidade de aprender a aprender, competência para agir na sala de aula, habilidades comunicativas, domínio da linguagem informacional, habilidades de articular as aulas com as mídias $\mathrm{e}$ as multimídias.

Será exigido desse novo professor um reaprendizado de suas habilidades e competências. O aluno contemporâneo preparado ou não para essa nova realidade tecnológica e comunicação vai depender do professor que lhe assiste, pois é ele que 
deveria estar preparado para o ensino. Capaz de entender o seu aluno em quaisquer circunstâncias em que ele esteja.

Dado o atual avanço tecnológico do século XXI, bem como as transformações causadas na Educação, se faz emergente a mudança de postura do professor. Percebese o que ocorre ultimamente, o docente está apenas adaptando os seus métodos usuais às novas tecnologias, às vezes por não dominar as novas tecnologias, às vezes pelo próprio medo de usá-las. Para Coelho e Haguenauer (2004):

[...] diante de toda a complexidade desse cenário globalizado e tecnologicamente avançado, os professores precisam empreender esforços para não só se inteirarem das formas de uso dessas ferramentas tecnológicas, mas também para identificar, nas potencialidades desses recursos, quais as implicações que elas trarão a sua postura profissional, ao seu trabalho docente e ao seu papel como educador.

No mundo globalizado não faz mais sentindo não estar tecnologicamente conectado. E a mudança de postura é uma decisão do próprio profissional, pois faz parte do seu papel de professor.

\subsection{FORMAÇÃO CONTINUADA DO PROFESSOR}

O aperfeiçoamento do professor é um requisito próprio dessa profissão. Com o passar dos tempos e as mudanças sociais e culturais causadas pelo processo de evolução tecnológica, afetam diretamente o mundo do trabalho. Por esse motivo o professor é um profissional em constante formação.

No Brasil, conforme Rodrigues e Silva (2015, p.562): “a Política Nacional de Formação de Professores pode ser tratada em dois níveis diferentes: a Formação Inicial do professor e a Formação Continuada em Serviço, que envolve mais de dois milhões de professores no sistema educativo nacional".
Presentemente, a necessidade de atualização dos professores é causada pela adequação tecnológica e a comunicação globalizada. O momento exigiu-se que o profissional esteja em conformidade com os hábitos da contemporaneidade. Para os autores Bottentuit Junior, Lisbôa e Coutinho (2012, p.192): "as TICs prometem desempenhar um papel significativo no desenvolvimento de competências e habilidades dos professores e alunos".

Com a presença das novas TDICs na escola e na vida dos jovens do mundo moderno, não há como a velha escola permanecer. De acordo com Libâneo (2011):

\footnotetext{
Diante da complexidade das relações comunicacionais no mundo contemporâneo, os educadores escolares precisam "aprender a pensar comunicações midiatizadas" como requisito para a formação da cidadania. Não basta que os professores disponham, na escola, dos meios de comunicação ou apenas saberem usálos.
}

Logo, o professor tem que estar em consonância com o mundo moderno, visto que a importância da escola na formação e construção do indivíduo como ser social, porque é através da escolarização que ele tem possibilidade se desenvolver e criar ferramentas que possam lhe facilitar o entendimento e o acesso a sociedade em que vive.

Seguidamente o aluno sair capacitado da escola conforme Bottentuit Junior, Lisbôa e Coutinho (2012, p. 192):

Isso exige que os alunos não apenas utilizem as ferramentas de maneira aleatória, mas que essa utilização seja reflexiva e criativa, bem como os seus conhecimentos acompanhem o ritmo das transformações e estejam em constante renovação, a fim de melhor se identificarem os métodos de ensino e aprendizagem, consoante às atuais mudanças. 


\subsection{A TEMÁTICA SAÚDE}

O conceito geral de saúde, em grande parte dos dicionários, define que: saúde é um estado do organismo que está em equilíbrio com o ambiente e habitualmente em equilíbrio mental, físico e psicológico. Para o indivíduo que vive em sociedade, ter essas condições também depende do meio em que ele vive, pelo fato de que a saúde está ligada diretamente a sua cultura e se ele vive em um ambiente desigual ele não estará em equilíbrio.

Segundo a Organização Mundial da Saúde (OMS), a saúde é definida como um estado de completo bem-estar físico, mental e social e não somente ausência de afecções e enfermidades, para ela:

A saúde passou, então, a ser mais um valor da comunidade que do indivíduo. É um direito fundamental da pessoa humana, que deve ser assegurado sem distinção de raça, de religião, ideologia política ou condição sócio-econômica. A saúde é, portanto, um valor coletivo, um bem de todos, devendo cada um gozá-la individualmente, sem prejuízo de outrem e, solidariamente, com todos.

A saúde é um direito de todos, porém nem todos entendem a abrangência de sua concepção. A temática "Saúde" é um conceito ainda percebido como sinônimo de doença e por esse motivo ele se torna um assunto pertinente à Educação. Segundo a Base Nacional Comum Curricular- BNCC (2018)

Conhecer-se, apreciar-se e cuidar de
sua saúde física e emocional,
compreendendo-se na diversidade
humana e reconhecendo suas emoções
e as dos outros, com autocrítica e
capacidade para lidar com elas.

Citada nas competências gerais da Base Nacional Comum Curricular, sendo assim uma temática que demanda uma urgência a ser esclarecida e, pois é por meio do seu entendimento uma possível mudança de paradigmas.

Portanto falar de saúde é uma questão social, essencial para o desenvolvimento da cidadania, pois envolve todos os âmbitos da vida humana em sociedade. É uma temática importante, de relevância social e cultural e por esse motivo o seu ensino é uma questão escolar. Demanda um planejamento específico.

\section{CAMINHO METODOLÓGICO}

A metodologia utilizada no trabalho foi de cunho qualitativo, resultado de uma pesquisa ação voltada para as tecnologias, culturas e saúde na escola realizadas na Escola Estadual X, situada numa zona rural na cidade de Uberaba-MG, com o propósito de apresentar um mapeamento da mesma. $\mathrm{O}$ ato de pesquisar está enraizado no homem, desde seus primórdios uma das principais técnicas de aquisição de conhecimento é a observação (DIONE; LAVILLE, 1999, p. 17-18).

Essa pesquisa foi realizada com o intuito de conhecer a realidade da escola observada sob os seguintes aspectos: cultura da escola e na escola, saúde e tecnologia no contexto escolar. Conforme Gatti (2007, p.9): "a pesquisa é o ato pelo qual procuramos obter conhecimento sobre alguma coisa [...] visando a criação de um corpo de conhecimento sobre certo assunto".

Os dados foram coletados através de observações, conversas informais com professores, bibliotecária, secretaria e a direção da escola. $O$ trabalho foi fundamentado em teorias e técnicas de pesquisa científica em educação. Observar a cultura da escola e na escola é o primeiro passo para tentar entender os significados da escola e dos seus membros, já que é levando em conta a cultura e a diversidade que se pode desvendar o homem e seus significados intrínsecos.

\subsection{CONTEXTOS DA PESQUISA}

A pesquisa foi realizada concomitante ao curso de especialização em Tecnologias Educacionais para a Prática Docente do Ensino em Saúde na 
Escola da Escola Nacional de Saúde Pública Sergio Arouca da Fundação Oswaldo Cruz (ENSP/FIOCRUZ). O período observado é referente ao ano letivo de 2018. A escola pesquisada está situada no município de Uberaba- MG. A escola está a $40 \mathrm{~km}$ do centro da cidade, funcionando num prédio alugado, no pátio de uma paróquia. A escola atende as seguintes etapas de ensino:

$>$ Ensino médio regular matutino

$>$ Ensino médio regular noturno

A observação ocorreu de acordo com o planejado. A recepção na escola foi bastante produtiva e receptiva, pois o diretor estava informado e bastante interessado, pois todo $\mathrm{o}$ processo foi acordado anteriormente.

\subsection{A PROPOSTA DE INTERVENÇÃO PEDAGÓGICA}

A presente proposta de intervenção é um projeto de formação para educadores com o intuito de desenvolver o uso das TDICs, para os professores da Escola X, visto que mesmo que a escolas possua equipamentos tecnológicos de informação e de comunicação, é sabido que estes equipamentos ainda não são aproveitados de forma adequada.

Juntamente com o uso das TDICs apresentar uma metodologia de ensino, que auxilie no desenvolvimento de uma temática como promoção de aprendizagem. Como metodologia de ensino entende-se, segundo Nérici (1989, p.53):

[...] nada mais é do que o conjunto de procedimentos didáticos, expressos pelos métodos e técnicas de ensino, que visam levar a bom termo a ação didática, que é alcançar os objetivos do ensino e, consequentemente, os da educação, com o mínimo de esforço e o máximo de rendimento.

Esta intervenção deseja contribui para a melhoria da prática pedagógica dos professores ao utilizarem as ferramentas tecnológicas disponíveis de forma produtiva por meio de novos métodos e técnicas de ensino, como as narrativas digitais. Segundo Cunha (1997, p.1-2): "usar narrativas como instrumento de formação de professores tem sido um expediente bem-sucedido".

A intervenção com o propósito de formação nomeada de "Narrativas digitais para o ensino da saúde na escola: uma proposta de intervenção voltada à formação de educadores" por meio das TDICs além de proporcionar uma nova prática, pode também possibilitar discussões acerca da metodologia. Ainda para Cunha (1997, p.12): "as inúmeras pesquisas qualitativas que se desenvolvem no Brasil, em especial na área de educação de professores, mostram que a teorização sobre esta metodologia vem crescendo, acompanhada de uma significativa prática investigatória”.

As narrativas digitais são comparadas ao antigo modo de ensinar, contando histórias. Porém, no universo das mídias as narrativas podem ser animadas, coloridas e no atual contexto da Web 2.0, existe aplicativos de vários formatos que possibilitam a criação de histórias.

O processo ocorrerá em modalidade de oficinas, a ser ministrado aos professores de todas as disciplinas na escola. A oficina será organizada da seguinte maneira:

Três sessões presenciais para a formação teórica e produção de materiais a serem utilizados e duas sessões online sincronizada, cada módulo presencial com o tempo estimado em 3 horas, divido em dois tempos e online com o tempo de duração de 1 hora.

$>$ No primeiro módulo: Atividades formativas teórica e prática por meio das TDICs em diversos ambientes.

$>$ No segundo módulo: Produção de trabalho, autônomo, para aplicação em contexto de sala de aula, das estratégias e recursos concebidos.

$>$ No terceiro módulo: Apresentação e avaliação das atividades e conteúdos produzidos e a avaliação dos trabalhos apresentado.

$>$ Duas sessões online sincrônicas para discussão do resultado da aplicação da prática didática e feedback dos alunos.

$>$ Auto avaliação. 


\subsection{TRATAMENTO E ANÁLISE DOS DADOS RESULTADOS ESPERADOS}

A elaboração de um relatório final com o resultado dos processos de avaliação e auto avaliação dos professores, bem como a análise do material produzido. Essa investigação contribuirá para a análise da discussão sobre a prática pedagógica entre pares.

A analisar o contexto, possibilitará identificar os problemas da implantação da metodologia. Nada mais oportuno do que autores e produtores descobrir no próprio trabalho suas fragilidades. $\mathrm{O}$ professor estuda a teoria, mas é na prática que ele consegue ver o resultado do seu trabalho, momento oportuno para a reflexão.

Visando uma mudança no processo ensino aprendizagem por meio TDICs, este trabalho pretende contribuir com adequação do uso das tecnologias na Escola $\mathrm{X}$ com o intuito de motivar as aulas, bem como promover a formação dos professores.

Sendo assim, percebida o sucesso da prática pedagógica com a melhoria do processo de ensino e aprendizagem e o aproveitamento ideal dos recursos tecnológicos, possibilitarem mudanças para que a escola se torne mais atrativa para os jovens do mundo moderno.

Diante do mundo atual, possibilitar ao professor a oportunidade de inovação, para que ele esteja em conformidade com seu aluno e não se torne obsoleto.

\section{CONCLUSÕES}

O trabalho pretende, acima de tudo, auxiliar na possibilidade de construção e mudanças de novas práticas pedagógicas no processo de ensino aprendizagem com o objetivo de melhoria no rendimento escolar e a adequação dos recursos tecnológicos disponíveis.

Todo projeto é um risco, é possível que este tenha falhas, porém é fomentado por meio de estudo, com base em pesquisas próprias da educação, contudo quando se trata da profissão docente é na sua prática que $\mathrm{o}$ profissional docente aprende a ensinar. Sendo assim os acertos e erros serão discutidos e debatidos para a produção de reflexão em torno do seu resultado.

Em suma, os resultados serão colhidos tão logo que aplicados, mediante o estudo, a análise e a reflexão pedagógica e metodológica. Com o uso adequado as tecnologias de informação e comunicação podem motivar professores e alunos no processo de ensino aprendizagem.

\section{REFERÊNCIAS}

BOTTENTUIT JUNIOR, João Batista; LISBÔA, Eliana Santana; COUTINHO, Clara Pereira. Narrativas Digitais na Formação Inicial de Professores: Um Estudo Com Alunos de Licenciatura em Pedagogia. Revista Teias, [S.1.], v. 13, n. 27, p. 14 pgs., abr. 2012. ISSN 1982-0305. Disponível em: <https://www.epublicacoes.uerj.br/index.php/revistateias/ar ticle/view/24260>. Acesso em: 02 jan. 2019.

BORGES, Maria Célia; AQUINO, Orlando Fernández; PUENTES, Roberto Valdés. Formação de Professores no Brasil: história, políticas e perspectivas. In: Revista

HISTEDBR On-line, Campinas, n.42, p.94-112, jun 2011. Disponível em <https://periodicos.sbu.unicamp.br/ojs/inde x.php/histedbr/article/view/8639868/7431> Acesso em: 12 agos.2018.

\section{COELHO, C. U. F.; HAGUENAUER,}

C. As tecnologias da informação e da comunicação e sua influência na mudança do perfil e da postura do professor.

Colabor@ - A Revista Digital da CVARICESU. Canoas-RS, v. 2, n. 6, 2004. Disponível em $<$ http://pEaD.ucpel.tche.br/revistas/inde x.php/colabora/index $>$ acesso em: $30 \mathrm{de}$ dezembro de 2018.

CUNHA, Maria Isabel da. Conta-me Agora!: As Narrativas Como Alternativas Pedagógicas na Pesquisa e no Ensino. Rev. 
Fac. Educ., São Paulo, v. 23, n. 1-2, p. , Jan. 1997 . Disponível em <http://www. scielo.br/scielo.php?script=sci_arttext\&pid= S0102-25551997000100010\&lng=en\&nrm =iso>. Acesso em: 02 Jan. 2019.

DIONE, Jean. LAVILLE, Christian. A construção do saber: manual de pesquisa em ciências humanas. Porto Alegre: Editora Artes Médicas. Belo Horizonte, 1999. P.17/49.

GATTI, Bernadete Angelina. A construção da pesquisa em Educação no Brasil. Brasília: Liber Livro, 2007.

GATTI, Bernardete Angelina; BARRETTO, Elba Siqueira de Sá; ANDRÉ, Marli Eliza Dalmazo de Afonso. Contexto contemporâneo, cultura, educação e políticas voltadas aos docentes. Políticas docentes no Brasil: um estado da arte. Brasília: UNESCO, 2011, p. 23-30.

Disponível em:

<http://unesdoc.unesco.org/images/0021/00 2121/212183por.pdf> Acesso em: 12. agos.2018.

LIBÂNEO, José Carlos. Adeus professor, adeus professora?. 13 ${ }^{\mathrm{a}}$ Ed.Cortez Editora. São Paulo, 2014.

LIBÂNEO, José Carlos. Organização e Gestão da Escola: Teoria e Prática. $5^{\circ} \mathrm{Ed}$. MF livros. Goiânia, 2008.

\section{MEC (2018). Base Nacional Comum}

Curricular. Ensino Médio. 2018. Brasília:

Secretaria de Educação Básica.

Disponível em

$<$ http://basenacionalcomum.mec.gov.br/ima ges/BNCC_EI_EF_110518_versaofinal_site .pdf > acesso em 09 de dez.2019.

MORAN, José Manoel. Novas tecnologias e o re-encantamento do mundo.

Revista Tecnologia Educacional. Rio de Janeiro, vol. 23, n.126, setembro-outubro 1995, p. 24-26.
NÉRICI, Imídeo. Metodologia de Ensino: Uma Introdução. $3^{\circ}$ Ed. Editora Atlas. São Paulo,1989.

RODRIGUEZ, Vicente; SILVA, Domingos Pereira da. Formação continuada em serviço em contextos descentralizados. Cad. CEDES, Campinas, v. 35, n. 97, p. 553-574, dezembro de 2015. Disponível em <http://www.scielo.br/scielo.php?script=sci _arttext\&pid=S0101-32622015000300553\& lng=en\&nrm=iso $>$. acesso em 01 de janeiro de 2019.

\section{SAVIANI, Dermeval. Formação de} professores: aspectos históricos e teóricos do problema no contexto brasileiro. Revista Brasileira de Educação v. 14 n. 40 jan./abr. 2009. Disponível em: <http://www.scielo.br /scielo.php?pid=S1413-4782009000100012 $\&$ script $=$ sci_abstract $\&$ tlng $=p t>$ Acesso em: 12. agost.2018.

SAÚDE. In: DICIO, Dicionário Online de Português. Porto: 7GRAUS, 2018.

Disponível em<https://www.dicio.com.br/ saude> Acesso em: 30/12/2018.

SETTON, Maria das Graças. Mídia e Educação. Editora Contexto. São Paulo, 2010.

VALENTE, José Armando; DE ALMEIDA, Maria Elizabeth Bianconcini. Narrativas digitais e o estudo de contextos de aprendizagem. EmRede - Revista de Educação a Distância, v. 1, n. 1, p. 32-50, 2014. 